\title{
A Needs Analysis Proposal for ESP: A Case Study of a Short English Training Course for Bank Tellers in a Chinese Bank
}

\author{
Dayan Liu1, Peng Zhang2 \\ ${ }^{1}$ School of Foreign Languages, Chongqing Jiaotong University, Chongqing, China \\ ${ }^{2}$ College of Interpreting and Translation, Sichuan International Studies University, Chongqing, China \\ Email:lucyldy2008@hotmail.com,pp9411@sisu.edu.cn
}

How to cite this paper: Liu, D. Y., \& Zhang, P. (2020). A Needs Analysis Proposal for ESP: A Case Study of a Short English Training Course for Bank Tellers in a Chinese Bank. Open Journal of Social Sciences, 8, 206-217.

https://doi.org/10.4236/jss.2020.87017

Received: April 26, 2020

Accepted: July 18, 2020

Published: July 21, 2020

Copyright () 2020 by author(s) and Scientific Research Publishing Inc. This work is licensed under the Creative Commons Attribution International License (CC BY 4.0).

http://creativecommons.org/licenses/by/4.0/

\begin{abstract}
Within the spectrum of English for Specific Purposes (ESP), needs analysis (NA) is the first and obligatory step. Based on NA studies, this paper makes an NA proposal for a short English training course for bank tellers in a Chinese bank to illustrate the actual implementation of NA procedures. This proposal pinpoints the NA types, sources of information and data-collection methods, with the rationale explained for those choices.
\end{abstract}

\section{Keywords}

Needs Analysis (NA), English for Specific Purposes (ESP), Triangulation, Observation Protocol

\section{Introduction}

The perception of English for Specific Purposes (ESP) has slightly varied. It is viewed as "a separate branch of English Language Teaching" (Dudley-Evans, 2001: p. 131) or "a pedagogical movement in applied linguistics" (Johns \& Price, 2014: p. 471). Generally, it recognizes learners' specific language needs, which are reflected in the development of specific approaches and materials, aiming to satisfy their present or future academic, vocational or professional purposes (Dudley-Evans, 2001; Johns \& Price, 2014).

The ways to classify ESP also vary. It is usually grouped into English for Academic Purposes (EAP) and English for Occupational Purposes (EOP), with a number of subdivisions (Dudley-Evens \& St John 1998; Dudley-Evans, 2001). Whatever the categories, since ESP is "tailored to the specific learning and language use needs and goals of identified groups of students" (Johns \& Price, 2014: 
p. 472), ESP courses of all sorts share the same important procedure, needs analysis (NA), which is the topic under discussion. This paper studies NA and presents an NA proposal for a short English training course for Chinese bank tellers. It first reviews NA, outlining different NA approaches and methods. It then proposes an NA for the specified training course, pinpointing its types, sources of information and data-collection methods and exploring the rationale for those choices.

\section{An Overview of Needs Analysis}

\subsection{Definition and Functions of Needs Analysis}

NA can be considered from both a broad and a narrow perspective. Most broadly speaking, NA is expected to cover "the full educational process", from setting the objectives all the way to teacher education (West, 1994: p. 12). In a narrow sense, NA is "a course development process", from which information can be obtained and used to determine or refine ESP course content and methods (Basturkmen, 2010: p. 19).

NA is an important procedure in ESP. Firstly, it distinguishes ESP from general English: general English tends to deal with "the presumed fundamentals of the language", whereas ESP is based on "a careful assessment of a particular group's specific language learning needs and target situation" (Johns \& Price, 2014: p. 472). Secondly, a number of researchers have asserted the central role of NA in ESP as a whole, as "the corner stone of ESP" (Dudley-Evans \& St John, 1998: p. 122), "the key defining feature of ESP" and always "the first step for ESP" (Dudley-Evans, 2001: p. 133). Others recognise its significance to ESP course design in particular, as "the irreducible minimum" (Hutchinson \& Waters, 1987: p. 53) and “a key instrument” (West, 1994: p. 2) of ESP course design. In short, Johns \& Price-Machada (2001: p. 49) confirm that "[In] every genuine ESP course, needs assessment is obligatory, and in many programs, an ongoing needs assessment is integral to curriculum design and evaluation”.

\subsection{Different Needs Analysis Approaches}

There is disagreement over what an NA should cover. This uncertainty in part stems from the indefinability of the term needs, which "remains at best ambiguous" (Richterich, 1983: 2, cited in West, 1994: p. 3). Given the ambiguity of needs, there are different approaches to NA. The author summarises and reviews some notable categories (see Figure 1), examined against the criteria of necessities, lacks, wants, the learner's English level, how to learn and other learner factors as well as environmental constraints.

Hutchinson \& Waters (1987) offer the broadest definition of Target Situation Analysis (TSA), covering necessities, lacks and wants, and asking questions about the target situation and participants' attitudes towards it. Those needs are sometimes nailed down as the language and skills needed in the target situation, the task and activities to use English. The first priority of Deficiency Analysis 


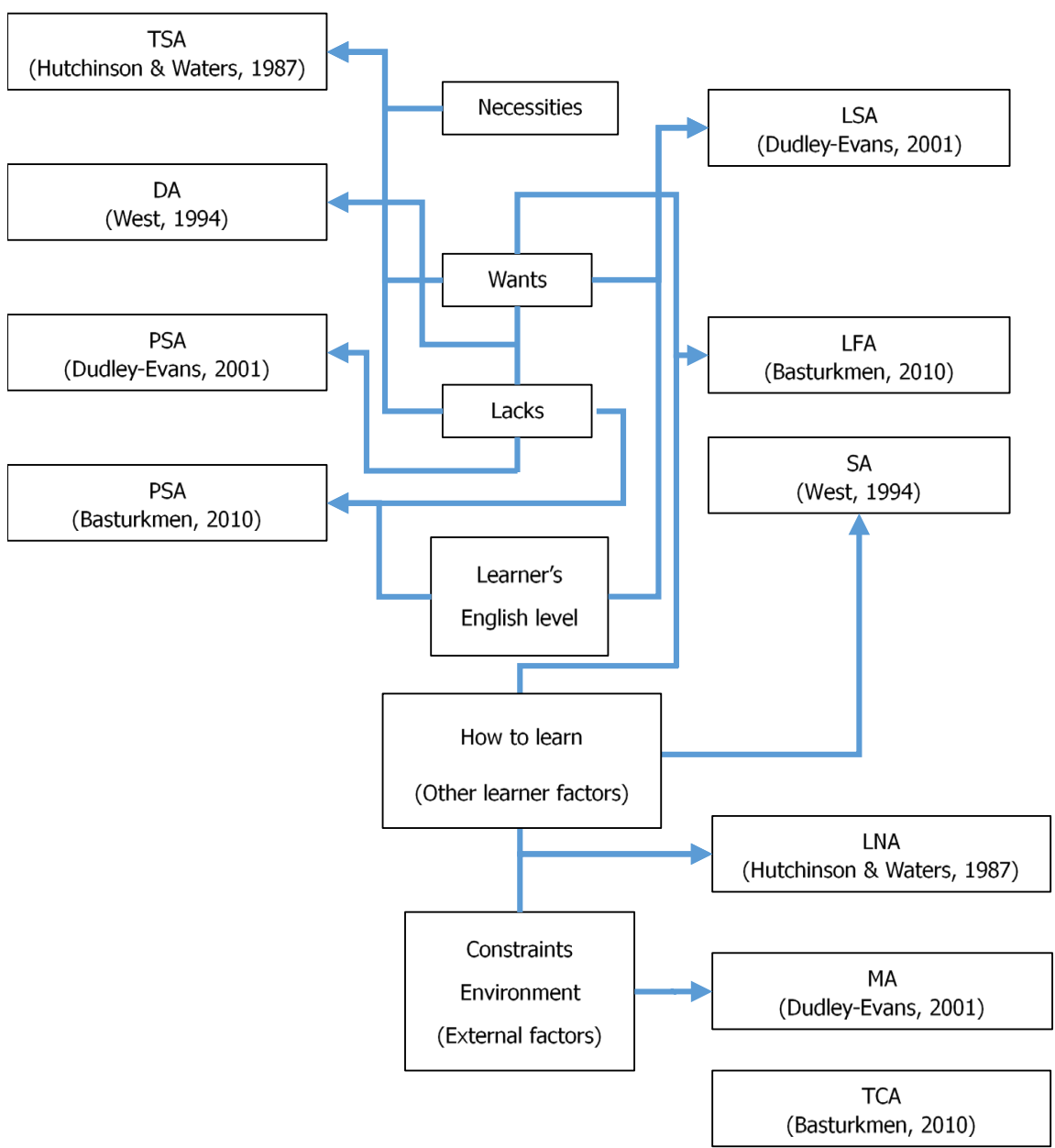

\section{Abbreviations}

TSA (target situation analysis)

PSA (present situation analysis)

DA (deficiency analysis)

LSA (learning situation analysis)

LFA (learner factor analysis)

SA (strategy analysis)

LNA (learning needs analysis)

MA (means analysis)

TCA (teaching context analysis)

Figure 1. An overview of NA approaches (devised by the author).

(DA) is to identify lacks or deficiencies, i.e. learners' "weaknesses in language and skills needed" (Dudley-Evans, 2001: p. 133). Directly related to DA is Present Situation Analysis (PSA), which, in Basturkmen's (2010: p. 19) view, covers both lacks and learners' current level of English. Learning Needs Analysis (LNA), Learning Situation Analysis (LSA) and Learner Factor Analysis (LFA) all deal with learner factors, such as the learning situation, the learners' level in English, motivations and their wants (Dudley-Evans, 2001). Means Analysis (MA) and Teaching Context Analysis (TCA) analyze the learning environment or practicalities, specifically within the teaching institution or company (Dudley-Evans, 2001). The analysis of strategies is covered in LNA, which distinguishes between 
learners' preferred learning strategies and teachers' perception of suitable strategies (Hutchinson \& Waters, 1987), but it is sometimes separately classed as Strategy Analysis (SA) (West, 1994; Johns \& Price, 2014). Other approaches may include the language audit (West, 1994), learners' composition (wide-angled/ heterogeneous or narrow-angled/homogeneous) (Johns \& Price, 2014).

All things considered, any approach alone cannot tell enough and all of them are useful in that ESP instructors can be guided by them to ascertain "their students' backgrounds, goals, and needs, and these findings determine the focus of the curriculum" (Johns \& Price, 2014: p. 478).

\subsection{Sources and Methods of Needs Analysis}

NA is generally accepted as the appropriate starting point for both curriculum design and materials writing. Whatever the approach, the NA procedure requires determining both the sources of information and the methods to collect data, as Long (2005: 62) puts it, "[When] NAs are conducted, their likely validity can be enhanced by careful attention to sources, methods, and source $\mathrm{x}$ method interactions".

\subsubsection{Sources of Information}

To decide the sources of information means to ask the question "Who should decide what the language needs are?” (West, 1994: p. 6). This step is of primary importance because "whoever determines needs largely determines which needs are determined" (Chambers, 1980: p. 27).

West (1994: p. 6) proposes "the needs analysis triangle" (see Figure 2), in which three major needs should be identified: teacher-perceived, student-perceived and company-perceived needs, for the three parties are expected to interact cooperatively. In his five-source list, Long (2005) adds to the "triangle" domain experts, literature, and triangulated sources. West (1994) also names other possible sources, such as former students, those already working in the target situation and specialist informants.

On the whole, Hutchinson \& Waters (1987: p. 60) support seeking answers "from a variety of sources" and attempting "a satisfactory compromise". This view is echoed by Long (2005: 63), who confirms that "multiple sources should always be employed, both because they add breadth and depth to an analysis,

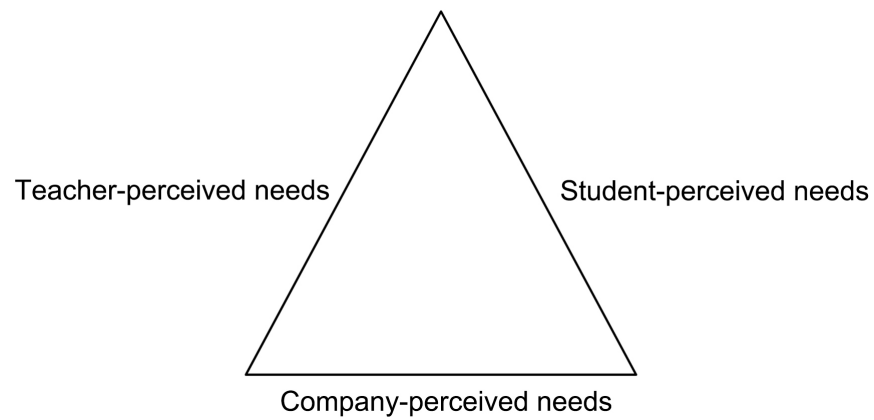

Figure 2. The needs analysis triangle (West, 1994: p. 6). 
and because triangulation of sources offers an important means of validating findings".

\subsubsection{Data-Collection Methods}

Given the complexity of needs to be diagnosed, Hutchinson \& Waters (1987) recommend a multi-method approach to NA. A key step is the selection of information-gathering instrument (West, 1994), which in a great measure determines the quality of the data (Basturkmen, 2010). A number of researchers have suggested some common methods for NA (see Table 1). Those techniques have both their pros and cons, as Long (2005: 30-31) explains, "some requiring more expertise or time than others, and some being more appropriate than others for different situations or for use with different kinds of informants". From the comparison of those methods, it is found out that questionnaires, interviews and observations are the three most common ones (for their pros and cons see Table 2 , for a detailed discussion see 3.3 in this paper).

\subsubsection{Triangulation of Sources and Methods}

Faced with the whole range of data-collecting methods for NA, Long (2005) suggests triangulation, which is a procedure involving comparisons of sources, methods, investigators, or even theories (Lincoln \& Guba, 1985), or which is simply "[The] combination of different sources for data to validate interpretations" (Perry, 2011: p. 261). The decision as to what type of data to collect and what methods to use is also subject to the availability of time and resources to conduct the NA (Hutchinson \& Waters, 1987). Each NA case is to some extent specific, in other words, "the method used in each case must be unique if it is to accommodate all the variables of persons, institutions, time and place" (Richterich, 1983: 9, cited in West, 1994: p. 7). This uniqueness can be seen in the following case study.

\section{A Proposed Needs Analysis for the Specified Training Course}

\subsection{The Context of the Course}

A Chinese commercial bank is contacting a language centre to discuss a short English training course for 20 newly-recruited college graduates who will work as tellers at the counter. As international business transactions and services in the bank are on the rise and problems dealing with non-Chinese speakers at the counter are increasingly reported, those novices are required to attend an English course as part of the on-the-job training scheme. After an unsuccessful English program last year with a different centre, the bank is now considering a one-month course with the focus placed on oral English skills.

\subsection{Selection of Participants}

In principle, all those newly-recruited tellers are expected to take the course. Specifically speaking, they satisfy the following conditions: 
Table 1. The commonly-used methods for NA (Hutchinson \& Waters, 1987; West, 1994; Long, 2005; Basturkmen, 2010).

\begin{tabular}{|c|c|c|c|c|}
\hline & West (1994) & Basturkmen (2010) & Hutchinson \& Waters (1987) & Long (2005) \\
\hline 1 & $\begin{array}{l}\text { surveys based on } \\
\text { questionnaires }\end{array}$ & questionnaires & questionnaires & surveys \& questionnaires \\
\hline 2 & structured interviews & interviews & interviews & $\begin{array}{l}\text { unstructured \& structured } \\
\text { interviews }\end{array}$ \\
\hline 3 & observation of classes & $\begin{array}{l}\text { observations of interactions } \\
\text { or ESP learners carrying out } \\
\text { tasks replicating those in the } \\
\text { target situation }\end{array}$ & observation & $\begin{array}{c}\text { participant \& non-participant } \\
\text { observation; classroom } \\
\text { observation }\end{array}$ \\
\hline 4 & & $\begin{array}{l}\text { analysis of language use in the } \\
\text { target situation }\end{array}$ & $\begin{array}{l}\text { data collection, } \\
\text { e.g. gathering texts }\end{array}$ & $\begin{array}{l}\text { analysis of discourse, } \\
\text { register/rhetoric, } \\
\text { computer-aided corpus, genre }\end{array}$ \\
\hline 5 & $\begin{array}{l}\text { pre-course placement/ } \\
\text { self-placement diagnostic tests; } \\
\text { entry tests on arrival }\end{array}$ & tests of performance & & $\begin{array}{l}\text { task-based, criterion-referenced } \\
\text { performance tests }\end{array}$ \\
\hline 6 & & & $\begin{array}{l}\text { informal consultations with } \\
\text { sponsors, learners and others }\end{array}$ & $\begin{array}{l}\text { non-expert \& expert } \\
\text { practitioner intuitions }\end{array}$ \\
\hline 7 & learner diaries & & & diaries, journals \& logs \\
\hline 8 & case studies & & & content analysis \\
\hline 9 & final evaluation/feedback & & & \\
\hline 10 & previous research & & & \\
\hline 11 & & & & $\begin{array}{l}\text { language audits; ethnographic } \\
\text { methods; role-plays, simulations; } \\
\text { triangulated methods }\end{array}$ \\
\hline
\end{tabular}

Table 2. The advantages and disadvantages of three major NA methods (adapted from Dörnyei, 2007; Basturkmen, 2010; Long, 2005; West, 1994).

\begin{tabular}{|c|c|c|}
\hline & Advantages & Disadvantages \\
\hline Questionnaires & $\begin{array}{l}\text { - suitable for a large number of people; } \\
\text { - not time-consuming or costly; } \\
\text { - plentiful focused, standardised and organised data; } \\
\text { - honest answers from respondents; } \\
\text { - conducted anonymously; } \\
\text { - less interviewer bias }\end{array}$ & $\begin{array}{l}\text { - idealised responses; } \\
\text { - a low rate of return; } \\
\text { - difficult to strike a balance between too many and too few } \\
\text { - } \text { questions; } \\
\text { - limited information and range of responses; } \\
\text { - lack of opportunity to clarify issues }\end{array}$ \\
\hline Interviews & $\begin{array}{l}\text { - helpful in collecting in-depth information; } \\
\text { - vague questions or answers able to be clarified; } \\
\text { - economy, familiarity, higher degree of co-operation, less } \\
\text { requirements of specialist training and the development } \\
\text { of a rapport }\end{array}$ & $\begin{array}{l}\text { - time-consuming; } \\
\text { - interviewer's bias and inconsistency; } \\
\text { - less standardized; } \\
\text { - quality of the data dependent on the interviewer's skills }\end{array}$ \\
\hline Observations & $\begin{array}{l}\text { direct, in-depth, contextualised study of } \\
\text { - participants' actual performances; } \\
\text { - the activities of interest in their natural environment }\end{array}$ & $\begin{array}{l}\text { unnatural environment and performances caused by the } \\
\text { presence of the outside observer in non-participant } \\
\text { observation }\end{array}$ \\
\hline
\end{tabular}


1) They have just graduated from college, majoring in different academic disciplines.

2) They have passed the College English Test Band 6 (CET6) or other national English tests for non-English majors or Test for English Majors-Band 8 (TEM8).

3) They are aged about 23, regardless of gender.

4) They are employed by the bank and will work as tellers at the counter.

5) They have already finished the 3-month pre-service training in the banking expertise required for the teller's job and qualified as novice tellers.

All of the participants meet those criteria, which serve as the standards for entry into the course.

\subsection{A Needs Analysis Proposal for the Course}

A language centre is entrusted with the instruction task. Before the commencement of the training program, as a crucial procedure, the language centre works with the bank to conduct a needs analysis in order to plan a completely workable and effective program.

In the needs analysis, the primary questions are: What sources of information should be included and what data-collection methods should be employed? In line with the aforementioned NA principles, it is desirable to have "the maximum number of sources of information if the identification of needs is to be reliable" (West, 1994: p. 6). Accordingly, some major methods are proposed for specific sources. The whole package of sources and methods is suggested in Table 3 (hereafter, source in the figure as S), with the rationale provided in the following.

Table 3. The NA proposal for a short English training coursefor bank tellers in a Chinese bank (designed by the author).

\begin{tabular}{|c|c|c|}
\hline Sources & Methods & Approaches \\
\hline S1: ESP teacher/applied linguists & - literature review & PSA; DA; LSA; SA \\
\hline & - questionnaire; & \\
\hline S2: novice bank tellers (learners) & $\begin{array}{l}\text { - observation (shadowing); } \\
\text { - test }\end{array}$ & PSA; DA; LSA; SA; LFA; LNA \\
\hline S3: supervisors (sponsors) & - interview & TSA \\
\hline $\begin{array}{l}\text { S4: veteran tellers } \\
\text { (domain experts) }\end{array}$ & $\begin{array}{l}\text { - interview; } \\
\text { - spoken or written reflections }\end{array}$ & TSA \\
\hline S5: bank clients & - questionnaire & TSA; DA; PSA \\
\hline S6: HR staff & - interview & PSA; DA; LSA \\
\hline S7: former ESP students & $\begin{array}{l}\text { - } \text { questionnaire } \\
\text { - spoken or written reflections }\end{array}$ & LFA; LNA; SA \\
\hline S8: bank training staff & - interview & MA; LFA; LNA; SA \\
\hline S9: administrative staff & $\begin{array}{l}\text { - interview; } \\
\text { - provide documents }\end{array}$ & $\begin{array}{c}\text { MA; } \\
\text { text analysis/discourse analysis }\end{array}$ \\
\hline
\end{tabular}




\subsubsection{Sources of Information Suggested}

Inspired by "the needs analysis triangle" (West, 1994), the three major sources are: first, the ESP teacher or applied linguist (Long, 2005), who is well-informed and experienced in language teaching; second, those novices as learners; third, the Chinese bank as the sponsor, with a supervisor as the representative responsible for contacting the language centre and setting the training objectives.

The "triangle" has limitations. ESP teachers do not seem to have so much knowledge or experience in a specialised field as domain experts and their intuitions are not solely reliable in course design and materials writing (Long, 2005). It is beneficial to seek information from learners, called "participatory needs analysis" (Robinson, 1991: 14, cited in West, 1994: p. 6), such as more realistic objectives, incremental learning and skills development, and relevance of classroom activities to real-life needs (Nunan, 1988). However, Long (2005: 27) warns against the dangers of using learners as sources, for those novices, as in-service learners, tend to "make excellent sources on the content of their job, training course, field of study, etc.", but are not so clear about their language needs.

Inasmuch as the triangle is inadequate, Long (2005) suggests another source, domain experts, namely, veteran tellers, who are equipped with expert insider knowledge and familiar with a teller's duties and activities. But they still run the risk of uncertainty about the language needs at specific linguistic levels and in higher discourse events (Long, 2005). Long (2005: 28) believes that having domain experts and applied linguists work together "can produce successful task-based language NAs". Under the multi-source theory (West, 1994; Hutchinson \& Waters, 1987; Long, 2005), other informants could include the clients of the bank, Human Resources (HR) staff, former ESP students, the bank training staff and the administrative staff.

\subsubsection{Sources and Methods Triangulated}

After the sources are pinned down, appropriate methods are selected for those data providers, chiefly questionnaires, interviews and observations (for their comparison see Table 2, for the triangulation see Table 3), presenting the views of different parties as to what language needs should be catered for.

\section{1) Questionnaires}

Administering a questionnaire is a quick and cheap procedure (Long, 2005), suitable for getting information from a large number of people (Dörnyei, 2007). Considering the number of respondents and the time available to deal with the data obtained, questionnaires can be used with the following informants:

a) $\mathbf{2 0}$ novice tellers (S2) to learn about their wants, their linguistic weaknesses and their preferred learning strategies, etc.;

b) bank clients (S5) selected by stratified sampling to learn their expectations of tellers and problems in the counter interactions with them;

c) former ESP students (S7) to learn about their learning experiences and outcomes. 
The data procured are plentiful and usually "focused, standardized, organized" (Long, 2005: 38). Respondents' answers are mostly honest, as this objectivity is in part guaranteed by anonymity (West, 1994). There will be less interviewer bias, since the questions, their sequence and the ways to phrase them are all precisely planned and set (Long, 2005). Questionnaires do have defects to be guarded against (see Table 2).

\section{2) Interviews}

Interviews are helpful in collecting in-depth information, in which responses can be probed and understood more deeply (Dörnyei, 2007). During an interview, vague questions are likely to be explained and answers clarified with the presence of both the interviewer and interviewee (West, 1994). Other positive points are familiarity, a higher degree of co-operation, little specialist training required (West, 1994). One notable flaw is that it is time-consuming (Dörnyei, 2007; for other defects see Table 2), which means that it is preferably used with a very small number of people. Therefore, this procedure is conducted with the following personnel:

a) one supervisor (S3) to learn their expectations and objectives;

b) one veteran teller (S4) to learn what language is needed in the target situation, especially an expert practitioner proficient at English, who can provide accurate information in this regard;

c) one member from the bank training staff (S8), a source to know the constraints and practicalities in the learning situation, the pre-service training experiences with those novices;

d) one member from the HR staff (S6), who can offer information about the learner profiles, their English proficiency, and more importantly, the complaints from clients about their counter interactions or the problems they often encounter there;

e) one member from the administrative staff (S9), especially the one in charge of property management, from whom to know what facilities the bank can offer for the course, the bank culture and the documents often used in the workplace.

It is recommended to use both questionnaires and interviews, exploiting the merits of each (West, 1994). The combined use of both takes different forms. In this case, due to the time constraint and workload, the two procedures are adopted simultaneously. Overall, they enable NA to "explore people's opinions of needs, difficulties and the importance of language skills and areas" (Basturkmen, 2010: p. 32).

\section{3) Observation}

Observation, also called "direct means" or “job-shadowing” (Basturkmen, 2010), is designated to investigate both actual language use and performances in the target situation, and is able to promote "direct, in-depth, contextualized study of what participants actually do, of the activities of interest in their natural environment" (Long, 2005: 42). 
Though positive results (e.g. Jasso-Aguilar, 1999) are reported, participant observation is much rarer than non-participant one in NA (Long, 2005). It is advisable to conduct a non-participant observation with those novices (S2), in which the teacher could observe them engage in interactions with the clients at the counter, or compare their performances with those of experienced tellers skilled in language use and communication. For the observation to be effective, an observation protocol is needed (for a sample see Figure 3, for the defects see Table 2).

Aside from the three, other applicable procedures might include: spoken or written reflections used with veteran tellers (S4) to summarise their in-service experiences, or with former ESP students (S7) to recapitulate their experiences on the previous ESP course (Basturkmen, 2010); tests used with learners (S2), thus "providing indicators of present needs or deficiencies" (West, 1994: p. 7); and literature survey by the teacher (S1) to gain insights from previous or similar programs (Long, 2005). In brief, all those informants and procedures triangulated can substantially enhance the credibility of the NA.

\section{Conclusion}

It is quite justifiable to assume that this NA framework is equally workable for other professions, in particular, working for department stores, restaurants, hotels, etc., regarding the training of newly-employed staff, if there is a similar need to improve their oral English skills in interactions with international clients. However, it is still advisable to tailor each program to its specific requirements and constraints, which fulfills the ultimate aim of English for specific purposes. Therefore, it is quite helpful to check the large store of literature for NAs in similar contexts (e.g. Edwards, 2000; Weninger \& Kan, 2013), which could serve as a starting point for one's own program, thus preventing the teacher from "reinventing the wheel" (Long, 2005: 25).

It should be noted that NA has limitations. West (1994) identifies some general areas, such as NA in general ELT and self-assessment of needs. There are

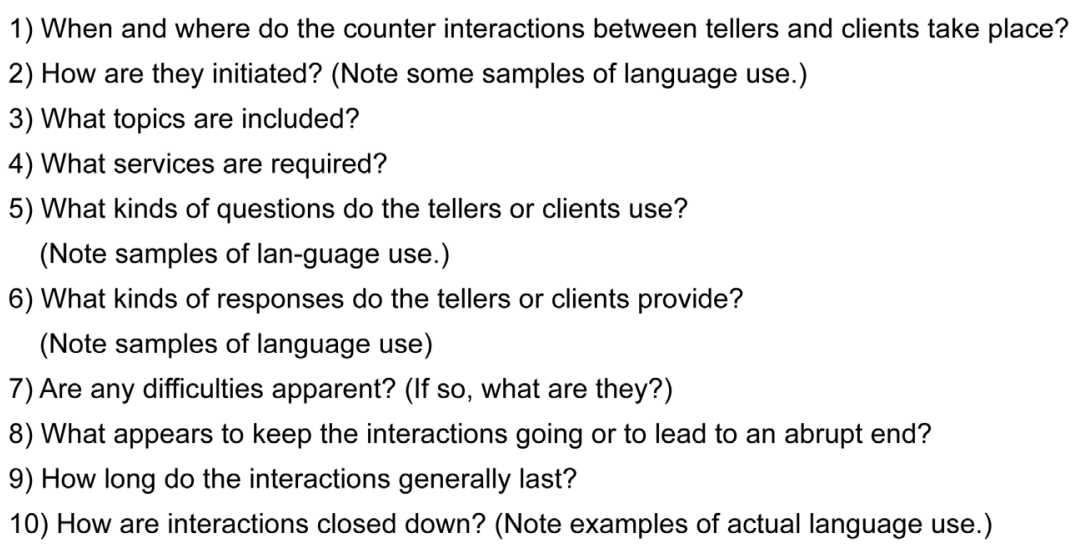

Figure 3. A sample observation protocol (adapted from Basturkmen, 2010: p. 33). 
also conflicts in NA, for instance, between objective and subjective needs (Hutchinson \& Waters, 1987), between theoretical principles and practical constraints (West, 1994), etc. Another issue that merits attention is that NA is not purely objective (Basturkmen, 2010) and neither is ESP, as it is concerned with people and is thus susceptible to "all the vagaries and foibles of human behaviour" (Hutchinson \& Waters, 1987: p. 60). For all the issues, the importance of NA cannot be over-emphasised, as Dudley-Evans (2001: p. 131) clearly states, "The key defining feature of ESP is that its teaching and materials are founded on the results of needs analysis".

\section{Conflicts of Interest}

The authors declare no conflicts of interest regarding the publication of this paper.

\section{References}

Basturkmen, H. (2010). Developing Courses in English for Specific Purposes. Basingstoke: Palgrave Macmillan. https://doi.org/10.1057/9780230290518

Chambers, F. (1980). A Re-Evaluation of Needs Analysis in ESP. The ESP Journal, 1, 25-33. https://doi.org/10.1016/0272-2380(80)90007-4

Dörnyei, Z. (2007). Research Methods in Applied Linguistics. Oxford: Oxford University Press. https://doi.org/10.1017/CBO9780511667206.020

Dudley-Evans, T. (2001). English for Specific Purposes. In R. Carter, \& D. Nunan (Eds.), The Cambridge Guide to Teaching English to Speakers of Other Languages (pp. 131 136). Cambridge: Cambridge University Press.

Dudley-Evans, T., \& St John, M. (1998). Developments in ESP: A Multi-Disciplinary Approach. Cambridge: Cambridge University Press.

Edwards, N. (2000). Language for Business: Effective Needs Assessment, Syllabus Design and Materials Preparation in a Practical ESP Case Study. English for Specific Purposes, 19, 291-296. https://doi.org/10.1016/S0889-4906(98)00029-5

Hutchinson, T., \& Waters, A. (1987). English for Specific Purposes. Cambridge: Cambridge University Press. https://doi.org/10.1017/CBO9780511733031

Jasso-Aguilar, R. (1999). Sources, Methods and Triangulation in Needs Analysis: A Critical Perspective in a Case Study of Waikiki Hotel Maids. English for Specific Purposes, 18, 27-46. https://doi.org/10.1016/S0889-4906(97)00048-3

Johns, A. M., \& Price, D. (2014). English for Specific Purposes: International in Scope, Specific in Purpose. In M. Celce-Murcia, D. M. Brinton, \& M. A. Snow (Eds.), Teaching English as a Second or Foreign Language (4th ed., pp. 471-487). Boston, MA: National Geographic Learning.

Johns, A. M., \& Price-Machada, D. (2001). English for Specific Purposes (ESP): Tailoring Courses to Students' Needs and to the Outside World. In M. Celce-Murcia (Ed.) Teaching English as a Second or Foreign Language (3rd ed., pp. 43-54). Boston, MA: Heinle and Heinle.

Lincoln, Y. S., \& Guba, E. G. (1985) Naturalistic Inquiry. Newbury Park, CA: Sage. https://doi.org/10.1016/0147-1767(85)90062-8

Nunan, D. (1988). The Learner-Centred Curriculum: A Study in Second Language Teaching. Cambridge: Cambridge University Press. 
https://doi.org/10.1017/CBO9781139524506

Perry, L. F. (2011). Research in Applied Linguistics: Becoming a Discerning Consumer (2nd ed.). Abingdon, VA: Routledge. https://doi.org/10.4324/9780203839027

Weninger, C., \& Kan, K. H.-Y. (2013). (Critical) Language Awareness in Business Communication. English for Specific Purposes, 32, 59-71. https://doi.org/10.1016/j.esp.2012.09.002

West, R. (1994). Needs Analysis in Language Teaching. Language Teaching, 27, 1-19. https://doi.org/10.1017/S0261444800007527 